\title{
The copper(II)-catalyzed oxidation of glutathione
}

\author{
Kamonwad Ngamchuea, Christopher Batchelor-McAuley, Richard G. Compton*
}

*corresponding author: Richard G. Compton, Department of Chemistry, Physical \& Theoretical Chemistry Laboratory, University of Oxford, South Parks Road, Oxford, OX1 3QZ, United Kingdom

Email: richard.compton@chem.ox.ac.uk. Tel: +44(0)1865275 957 Fax: +44(0)1865275410

\begin{abstract}
The kinetics and mechanisms of copper(II)-catalyzed GSH oxidation are examined in the light of its biological importance and in the use of blood and/or saliva sample for GSH monitoring. The rates of 'free thiol' consumption were measured spectrophotometrically via reaction with DTNB, showing that GSH is not auto-oxidized by oxygen in the absence of a catalyst. In the presence of $\mathrm{Cu}^{2+}$, reactions with two timescales were observed. The first step (short timescale) involves the fast formation of a copper-glutathione complex via the cysteine thiol. The second step (longer timescale) is the overall oxidation of GSH to GSSG catalyzed by copper(II). When the initial concentrations of GSH are at least three-fold in excess of $\mathrm{Cu}^{2+}$, the rate law is deduced to be $-\mathrm{d}[$ thiol $] / \mathrm{dt}=k$ [copper-glutathione complex $]\left[\mathrm{O}_{2}\right]^{0.5}\left[\mathrm{H}_{2} \mathrm{O}_{2}\right]^{-0.5}$. The order of reaction with respect to $\mathrm{O}_{2}$ of $0.5^{\text {th }}$ reveals a pre-equilibrium prior to the ratedetermining step of GSSG formation. In contrast to $\left[\mathrm{Cu}^{2+}\right]$ and $\left[\mathrm{O}_{2}\right]$, the rate of reactions decreases with increasing concentrations of GSH. This inverse relationship is proposed to be a result of competing formation of an inactive form of copper-glutathione complex (binding to glutamic and/or glycine moieties).
\end{abstract}

\section{Keywords}

Autoxidation, metal catalyst, reaction mechanisms, complex rearrangement, kinetics. 


\section{Introduction}

Glutathione is the most abundant thiol compound in animals and plants. Its reduced form functions as a cellular antioxidant, preventing oxidative damage caused by xenobiotic and endogenous reactive oxygen and nitrogen species. For this purpose, the level of reduced glutathione in biological subjects must be maintained, for example, at ca. $1.0 \mathrm{mM}$ and $15 \mu \mathrm{M}$ in human blood and saliva respectively. ${ }^{[1]}$ Changes in reduced glutathione (GSH) concentrations in biological fluids are auxiliary diagnostic of health status as well as various diseases. The stability of GSH concentrations in the samples collected is thus highly important for the accuracy of blood and non-invasive saliva sensing technology.

There are several parameters which can affect the levels of reduced glutathione in biological systems. One of the influential factors, and the focus of this paper, is the consumption of reduced glutathione via reactions, both stoichiometric and catalytic, with copper(II) ions. This reaction is of direct physiological relevance for certain diseases such as Wilson's disease, where the amount of copper(II) in blood is present in excess. ${ }^{[2]}$ In such cases, haemolytic anemia may be induced by the decreased level of reduced glutathione. From the above reports, it may be proposed that the toxicity of copper is a consequence of glutathione and copper(II) reaction. However, the co-existence of glutathione and copper can inhibit the formation of reactive radicals by the stabilization of copper(I) with reduced glutathione. ${ }^{[3]}$ The presence of GSH has also been used as an anti-oxidant in the prevention of copperdependent DNA damage. ${ }^{[4]}$

All of these properties are consequences of the formation of copper-glutathione complex and the depletion of reduced glutathione by oxidation reaction to its oxidized form, GSSG. Despite the biological importance, the mechanistic details of these processes have been unclear for decades. The previously suggested mechanisms include the simple redox process of $\mathrm{Cu}^{2+}$ and $\mathrm{GSH}$ to $\mathrm{Cu}^{+}$and GSSG. ${ }^{[5]}$ The more complex mechanisms proposed involve detailed studies of the formation of different possible radical species due to much interest in the radical reactivity within the biological systems. ${ }^{[6]}$ Studies based on GSSG formation and $\mathrm{O}_{2}$ consumption have also been reported. ${ }^{[7]}$ However, the stoichiometry as well as the kinetics of the reaction is unknown. Therefore, the re-evaluation of the fundamental mechanisms of GSH oxidation catalyzed by $\mathrm{Cu}(\mathrm{II})$ is required.

In this paper, we consider exclusively the situation where GSH is in excess to focus on the 'catalytic' behaviour of copper(II) and to mimic physiological conditions where GSH is usually in large excess. The copper-glutathione complex formation is monitored by UV-Vis spectrophotometry at a number of different times during the reaction. The concentrations of free thiols, including free GSH and GSH bound to copper(II) via the non-thiol sites, are determined by reactions with DTNB to form a coloured TNB species $(\varepsilon \lambda=412 \mathrm{~nm}=14,150$ $\left.\mathrm{cm}^{-1}\right){ }^{[8]}$ The change in absorbance values at $412 \mathrm{~nm}$ with experimental time is studied and the rate of consumption of free thiols assessed. The variation in rates as a function of different experimental parameters is analyzed to yield the kinetics of the reaction.

The order of reaction with respect to the concentration of oxygen is determined and a preequilibrium step prior to the production of GSSG revealed. We further observed the intriguing apparent inverse relationship of the reaction rate with GSH concentrations. Consequently, this provides an insight into the formation and further rearrangement of copper-glutathione complexes. As a result, we propose the mechanisms of copper(II)catalyzed GSH oxidation which will help to gain better understandings of the role of GSH as well as copper(II) in biological systems. 


\section{Experimental}

\subsection{Chemical Reagents and Instrumentation}

All reagents were purchased from Sigma-Aldrich and were used as supplied without further purification; reduced L-glutathione (GSH, $\geq 98.0 \%$ ), copper(II) nitrate trihydrate $\left(\mathrm{CuNO}_{3} \cdot 3 \mathrm{H}_{2} \mathrm{O}\right.$, puriss. p.a., 99-104\%), 5,5'-dithiobis(2-nitrobenzoic acid) (DTNB, $\geq 98 \%$ ), sodium phosphate dibasic $\left(\mathrm{Na}_{2} \mathrm{HPO}_{4}, \geq 99.0 \%\right)$ and sodium phosphate monobasic dihydrate $\left(\mathrm{NaH}_{2} \mathrm{PO}_{4} \cdot 2 \mathrm{H}_{2} \mathrm{O}, \geq 99.0 \%\right)$. Solutions were prepared using deionised water (Millipore) with a resistivity of $18.2 \mathrm{M} \Omega \mathrm{cm}$ at $25^{\circ} \mathrm{C}$.

All measurements were performed with a Shimadzu UV-1800 UV-Vis spectrophotometer using a temperature controlled cell holder. All reaction mixtures were thermostated at $25{ }^{\circ} \mathrm{C}$.

\subsection{Methods}

Copper-glutathione complex formation was monitored as a function of time using UV-Vis spectrophotometry in the range of wavelengths of $250 \mathrm{~nm}$ to $1,000 \mathrm{~nm}$.

The concentrations of reduced glutathione (GSH) were determined by the reaction with Ellman's reagent (DTNB) producing a coloured product, TNB, which has a strong absorbance at $412 \mathrm{~nm}$; refer to eqn. 1. The UV-Vis spectra were recorded over the course of the experiment and the absorbance values at $412 \mathrm{~nm}$ plotted against time.

$$
\mathrm{DTNB}+\mathrm{GSH} \longrightarrow \mathrm{GS}-\mathrm{TNB}+\mathrm{TNB}\left(\varepsilon \lambda=412 \mathrm{~nm}=14,150 \mathrm{~cm}^{-1}\right)^{[8]}
$$

All the reactions involving glutathione and copper(II) took place in aqueous solution without the presence of other possible interferences such as buffers, which could potentially form a complex with copper. Nonetheless, the measurement of free thiol concentration requires the presence of (phosphate) buffer for the thermodynamically-driven reaction of thiols with DTNB. ${ }^{[9]}$ Hence, solutions of the reaction mixture (unbuffered) and DTNB (in phosphate buffer $\mathrm{pH}$ 7) were used and allowed to $\operatorname{mix}$ for $2 \mathrm{~min}$ prior to the measurements for absorbance at $412 \mathrm{~nm}$ to reach its stable value; see Supporting Information.

\section{$3 \quad$ Results and Discussions}

In this study, aqueous solutions of excess GSH and $\mathrm{Cu}^{2+}$ were allowed to mix in the absence or presence of $\mathrm{O}_{2}$. The rates of the reactions were then determined by monitoring of either the changes in GSH concentrations or the copper-glutathione complex formation as a function of time. The kinetics of the reactions was investigated by analyzing the dependence of the rates of GSH oxidation on the concentrations of $\mathrm{Cu}^{2+}, \mathrm{O}_{2}$ and GSH.

For the monitoring of GSH concentrations, the DTNB measurement method was first validated. Variable concentrations of standard GSH solutions $(0.5-60 \mu \mathrm{M})$ were mixed with excess DTNB $(87 \mu \mathrm{M})$ in phosphate buffer $(\mathrm{pH} \mathrm{7)}$. The UV-Vis spectra of the reaction mixtures and the linear calibration plot of absorbance values at $412 \mathrm{~nm}\left(\mathrm{~A}_{412}\right)$ as a function of GSH concentration are given in the Supporting Information. However, DTNB is not specific to GSH. The concentration of the species measured from $\mathrm{A}_{412}$ thus will be referred to as that of 'free thiols' or '-SH' throughout this paper.

Using the validated DTNB method, buffered DTNB was added to aliquots of the reaction mixtures every 4 or 8 min to assess the levels of $-\mathrm{SH}$ in three different sets of experiments. 
First is the study of GSH auto-oxidation; that is the oxidation of GSH in the presence of $\mathrm{O}_{2}$ but in the absence of $\mathrm{Cu}^{2+}$. Second, the reaction between $\mathrm{GSH}$ and $\mathrm{Cu}^{2+}$ is investigated in the absence of $\mathrm{O}_{2}$. Third, the oxidation of GSH is studied in the presence of both $\mathrm{Cu}^{2+}$ and $\mathrm{O}_{2}$.

All the three situations above give rise to different patterns of reactivity and will be discussed next. In the following experiments performed in the presence of copper(II) catalyst, the kinetic data reveal two distinct timescales for the reactions. In the absence of $\mathrm{O}_{2}$, the reaction occurring at a short timescale is referred to as step ' $x$,' while that occurring at a long timescale is called step ' $y$.' In the presence of $\mathrm{O}_{2}$, steps ' $\mathrm{X}$ ' and ' $\mathrm{Y}$ ' designate the reactions occurring at short and long timescales respectively.

\subsection{GSH oxidation in the presence of $\mathrm{O}_{2}$, but in the absence of $\mathrm{Cu}^{2+}$}

The concentration of reduced glutathione in aqueous solution in the presence of atmospheric oxygen $\left(0.27 \mathrm{mM} \mathrm{O}_{2}\right)^{[10]}$ was measured as a function of time. The results showed that the GSH concentration is extremely stable in the absence of added metal catalysts, with the rate of GSH consumption as low as $6.6 \mathrm{nM} \mathrm{min}{ }^{-1}$ for the starting GSH concentration of $56 \mu \mathrm{M}$.

However, we note that there is a $\leq 0.01 \mu \mathrm{M}$ trace impurity of copper present in the solution (calculated from $\leq 0.0005 \%$ copper stated by Sigma-Aldrich). It was therefore further investigated if the slow oxidation of GSH observed in the absence of 'added' catalyst is a result of catalytic activity of the trace amount of copper(II) present. For this purpose, $\mathrm{Cu}^{2+}$ impurities in the GSH solution were removed by the addition of excess EDTA. The concentration of GSH in the reaction mixtures of $1.0 \mathrm{mM}$ EDTA and $56 \mu \mathrm{M}$ GSH was then measured at different times. At these concentrations, over $99.99 \%$ of $\mathrm{Cu}^{2+}$ are bound to EDTA (from the value of stability constant of the $\mathrm{Cu}(\mathrm{II})-$ EDTA complex formation of $10^{18.80}{ }^{[11]}$ and hence no longer available to participate in reactions with GSH. The result shows that the concentration of GSH is constant for the three hours studied with the experimental errors of less than $\pm 2 \%$. It thus can be deduced that a metal catalyst is required for GSH to be oxidized by oxygen at noticeable rates and that 'auto-oxidation' is unlikely, as reported previously by Warburg. ${ }^{[12]}$ Furthermore, it is noted that the rate of GSH oxidation of $6.6 \mathrm{nM} \mathrm{min}^{-1}$ for the $56 \mu \mathrm{M} \mathrm{GSH}$ solution (as presented at the beginning of this section) corresponds to sub-ten nanomolar concentration of $\mathrm{Cu}^{2+}$, as estimated from the results that will be demonstrated later in Section 3.3a. The estimated concentration of $\mathrm{Cu}^{2+}$ is in good agreement with the manufacturer suggested concentration of the copper(II) impurities in solution.

\subsection{GSH oxidation in the presence of $\mathrm{Cu}^{2+}$, but in the absence of $\mathrm{O}_{2}$}

The concentrations of -SH were measured at different experimental times (every 4 or 8 min) after the deoxygenated solutions of $\mathrm{Cu}^{2+}$ and GSH were mixed in the absence of $\mathrm{O}_{2}$. The experiments using $95 \mu \mathrm{M}$ GSH and varied concentrations of $\mathrm{Cu}^{2+}(2.5 \mu \mathrm{M}, 12.5 \mu \mathrm{M}$ and $17.5 \mu \mathrm{M}$ ) were performed to study the stoichiometric ratio of Cu:GSH. Meanwhile, the fixed $\mathrm{Cu}^{2+}$ concentration of $5 \mu \mathrm{M}$ and varied concentrations of GSH $(56 \mu \mathrm{M}, 85 \mu \mathrm{M}$ and $110 \mu \mathrm{M})$ were used in the study of the effect of GSH concentrations on the rates of changes in $-\mathrm{SH}$ concentration.

The kinetic studies revealed two-step reactions (i.e. reactions with two different timescales). The first step, labelled as step ' $x$ ' in Figure 1, showed a fast decrease in free thiols or $-\mathrm{SH}$ concentration when $\mathrm{Cu}^{2+}$ were added to the solution of GSH by the amount that is equal to one equivalent of $\mathrm{Cu}^{2+}$ used; please refer to Figure 1a. 
Following the fast drop in $-\mathrm{SH}$, there is a slow increase in $-\mathrm{SH}$ as time progresses, the process of which is referred to as 'step y.' The rate of -SH released from the Cu-SG complex in step $y$ is dependent on the concentration of GSH; refer to Figure $1 \mathrm{~b}$.
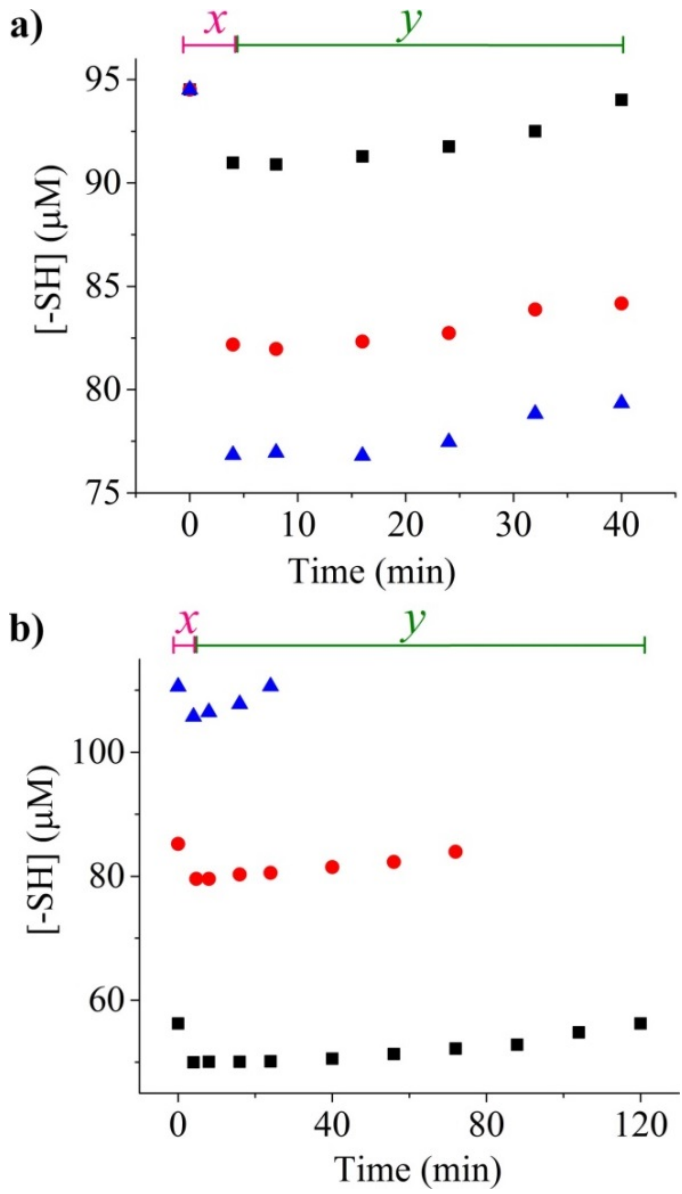

Figure 1: The concentrations of free thiols $(-\mathrm{SH})$ at different experimental times for a) deoxygenated, $95 \mu \mathrm{M}$ GSH, varied concentrations of $\mathrm{Cu}^{2+}: 2.5 \mu \mathrm{M}$ (black), $12.5 \mu \mathrm{M}$ (red) and $17.5 \mu \mathrm{M}$ (blue); b) deoxygenated, $5 \mu \mathrm{M} \mathrm{Cu}^{2+}$, varied concentrations of GSH: $56 \mu \mathrm{M}$ (black); $85 \mu \mathrm{M}$ (red); $110 \mu \mathrm{M}$ (blue)

The decrease in -SH concentration observed in step $x$ may be a result of either the fast oxidation of GSH to GSSG catalyzed by $\mathrm{Cu}^{2+}$ or the formation of copper-glutathione complex via the thiol group; both processes of which would result in the loss of 'free' thiols. In order to elucidate this process further, the UV-Vis spectra of different copper-glutathione complexes without the inclusion of DTNB were studied and are described next.

The UV-Vis spectra of the species involved in the reaction were recorded and are displayed in Figure 2. $\mathrm{Cu}^{2+}$ and GSH showed no observable absorption in the wavelength range of interest, $250-350 \mathrm{~nm} .^{[13]}$ GSSG exhibited a strong absorption at wavelengths below $\sim 270 \mathrm{~nm}$. The addition of $\mathrm{Cu}^{2+}$ to the solution of GSSG results in the reduction of absorbance in that region. This is possibly a result of the formation of $\mathrm{Cu}^{2+}$ - GSSG complex, which does not have strong absorption in this long-wavelength UV region. Proposed structures of $\mathrm{Cu}^{2+}$-GSSG complexes have been reported. ${ }^{[14]}$ Meanwhile, the strong absorption observed at $297 \mathrm{~nm}$ in the spectra of $\mathrm{Cu}^{2+}$ and GSH mixtures is ascribed as relating to the formation of copper-reduced glutathione complex, ${ }^{[12]}$ the structure of which is unconfirmed and discrepancy exists in the literature. ${ }^{[15]}$ 
From the rapid increase in absorption at $297 \mathrm{~nm}$ when $\mathrm{Cu}^{2+}$ is added to the GSH solution and the stoichiometry between $\mathrm{Cu}^{2+}$ and GSH of 1:1 determined earlier, the fast drop in -SH concentration in step $x$ is concluded to be a result of the formation of 1:1 Cu-SG complex via the cysteine moiety (eqn. 2).

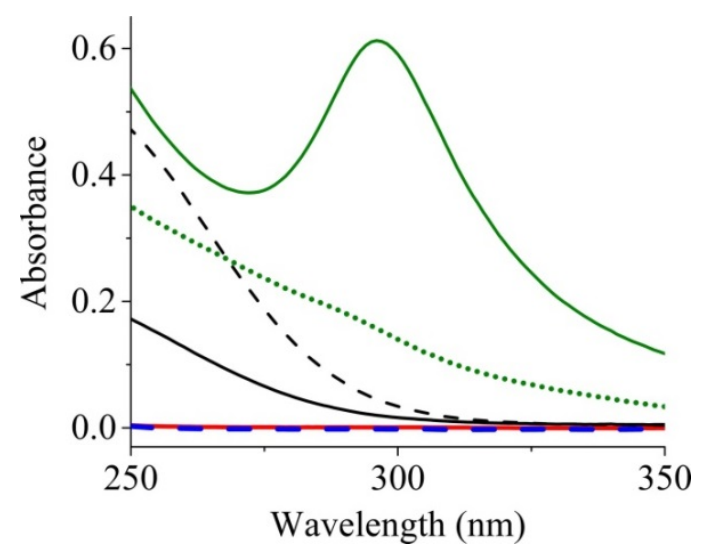

Figure 2: UV-Vis spectra of $60 \mu \mathrm{M} \mathrm{Cu}^{2+}$ (red); $600 \mu \mathrm{M}$ GSH (aq) (dashed blue); $300 \mu \mathrm{M}$ GSSG (aq) (dashed black); $300 \mu \mathrm{M}$ GSSG and $60 \mu \mathrm{M} \mathrm{Cu}^{2+}$ (aq) (solid black; remain unchanged with time); $600 \mu \mathrm{M}$ GSH and $60 \mu \mathrm{M} \mathrm{Cu}^{2+}$ (aq) after mixing for 30 sec (dotted green) and 40 min (solid green)

An increase in free -SH concentration with time was observed in step y reaction (Figure $1 \mathrm{~b}$ ). This implies that there is a release of the thiol group initially bound to copper. We therefore propose the rearrangement of copper-glutathione complex from thiol-bound to glutamic/glycine-bound as the mechanism contributing to this phenomenon. The other routes such as the loss of $\mathrm{Cu}^{2+}$ availability in solutions have also been considered and were eliminated due to opposing evidences. Specifically, the alternate mechanisms were demonstrated to play a very minor role or not to be thermodynamically favourable. We will return to these alternate mechanistic pathways towards the end of the text.

The rate of freeing the thiol groups depends on the concentration of GSH (step $y$, figure 1b), suggesting the involvement of GSH and not simply the loss of $\mathrm{Cu}^{2+}$. More importantly, this dependence on the GSH concentration indicates that the process proceeds via an intermolecular rather than intramolecular mechanism. Consequently, the copper-sulfur bond of the Cu-SG complex is concluded to be dissociated before the slow, thermodynamically favourable re-combination of $\mathrm{Cu}$ with GSH through the glutamic and/or glycine moieties takes place (eqn. 3).

$$
\begin{aligned}
& \mathrm{Cu}^{2+}+\mathrm{GSH} \stackrel{\text { fast }}{\rightleftharpoons} \mathrm{Cu}^{2+}-\mathrm{S}(\mathrm{H}) \mathrm{G} \\
& \mathrm{Cu}^{2+}+\mathrm{GSH} \stackrel{\text { slow }}{\rightleftharpoons} \mathrm{Cu}^{2+}-\mathrm{GSH}
\end{aligned}
$$

The existence of the rearrangement pathway for the copper-glutathione complex is further corroborated by the following observation made in the literature. It has been reported that GSH is a versatile ligand that can bind to GSH to glutamic moiety as well as the thiolate sulfur. ${ }^{[16]}$ There is also a report on the complex formation between copper(II) and glutamic acid. ${ }^{[17]}$ The versatility of GSH ligand is further demonstrated by the fast rate of exchange of GSH with Cu-SG which was reported to be $13 \mathrm{~s}^{-1}$. ${ }^{[18]}$ Furthermore, the rates of thiol oxidation processes catalyzed by copper(II) are significantly different for different thiols such 
as glutathione and cysteine. ${ }^{[19]}$ This indicates the involvement of the glutamic and/or glycine moieties in the formation of complex of copper(II).

\subsection{GSH oxidation in the presence of both $\mathrm{Cu}^{2+}$ and $\mathrm{O}_{2}$}

Solutions of $\mathrm{Cu}^{2+}$ and GSH were mixed under different reaction conditions (detailed in separate sections below) in the presence of atmospheric $(0.27 \mathrm{mM})^{[10]}$ or saturated $(1.24 \mathrm{mM})^{[20]}$ oxygen. The concentrations of free $-\mathrm{SH}$ were monitored as a function of time. The results revealed two-step reactions (i.e. reactions with two different timescales) designated as $\mathrm{X}$ and $\mathrm{Y}$ (Figure 3), described next.

\section{Step X: short timescale reactions}

Solutions of fixed GSH concentration and varied concentrations of $\mathrm{Cu}^{2+}$ were mixed in the presence of atmospheric $\mathrm{O}_{2}$ to yield the final concentrations of $56 \mu \mathrm{M}$ GSH and $0 \mu \mathrm{M}, 2 \mu \mathrm{M}$, $5 \mu \mathrm{M}$ and $10 \mu \mathrm{M} \mathrm{Cu}^{2+}$. Similar experiments were performed for a high GSH concentration $(600 \mu \mathrm{M})$ with $0 \mu \mathrm{M}, 60 \mu \mathrm{M}, 150 \mu \mathrm{M}$ and $300 \mu \mathrm{M} \mathrm{Cu}^{2+}$. The concentrations of free $-\mathrm{SH}$ were monitored for $40 \mathrm{~min}$ after the solutions were mixed.

The plots of -SH against time in Figure 3 show that in the first step ("step X") there is a fast drop in concentration of - $\mathrm{SH}$ analogous to that observed earlier. However, the stoichiometry of Cu:GSH is now 1:2 (Figure 3), in contrast to the 1:1 observed in the absence of $\mathrm{O}_{2}$ (Figure 1a).

The dependency of the stoichiometry on oxygen implies that GSH first forms a 1:1 Cu:SG complex via the thiol group of glutathione in a very fast timescale. The binding of the second GSH molecule to copper via the thiol group requires the presence of oxygen, suggesting that the 1:2 Cu:SG complex is relatively unstable without electron transfer with oxygen; refer to eqn. 4 and 5. The electron transfer results in the formation of one of the oxidized forms of the 1:2 Cu:SG complex. For the moment, we call this complex 'A,' the identity of which is proposed and presented later on in the text (Figure 8).

$$
\begin{aligned}
& \mathrm{Cu}^{2+}-\mathrm{S}(\mathrm{H}) \mathrm{G}+\mathrm{GSH} \stackrel{\mathrm{G}(\mathrm{H}) \mathrm{S}-\mathrm{Cu}^{2+}-\mathrm{S}(\mathrm{H}) \mathrm{G}}{\longrightarrow} \mathrm{A}+1 / 2 \mathrm{H}_{2} \mathrm{O}_{2} \\
& \mathrm{G}(\mathrm{H}) \mathrm{S}-\mathrm{Cu}^{2+}-\mathrm{S}(\mathrm{H}) \mathrm{G}+1 / 2 \mathrm{O}_{2} \stackrel{\text { fast }}{\rightleftharpoons} \mathrm{A}
\end{aligned}
$$

\section{Step Y: long timescale reactions}

In this section, we will focus on the second step ("step Y") of the results obtained from the experiments performed in the previous section (refer to Figure 3). During step Y, there is a linear decrease in - $\mathrm{SH}$ concentration with time, suggesting the overall reaction is zeroth order. To investigate the kinetics of the slower step $\mathrm{Y}$ reaction, the concentrations of $\mathrm{Cu}^{2+}, \mathrm{O}_{2}$ and GSH were varied to evaluate how the rate depends on the concentration of each species. 

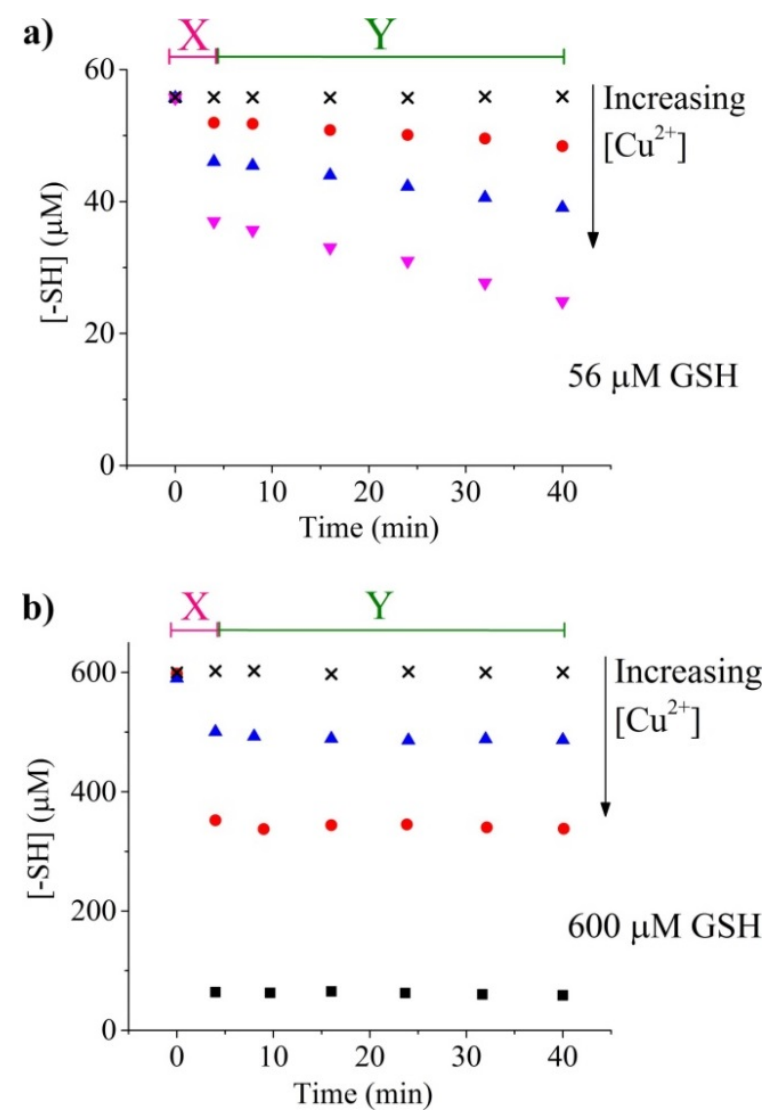

Figure 3: The concentrations of free thiols (-SH) at different experimental times; a) $56 \mu \mathrm{M}$ GSH, atmospheric $\mathrm{O}_{2}$, varied concentrations of $\mathrm{Cu}^{2+}: 0 \mu \mathrm{M}$ (cross); $2 \mu \mathrm{M}$ (red); $5 \mu \mathrm{M}$ (blue); $10 \mu \mathrm{M}$ (pink); b) $600 \mu \mathrm{M}$ GSH, atmospheric $\mathrm{O}_{2}$, varied concentrations of $\mathrm{Cu}^{2+}: 0 \mu \mathrm{M}$ (cross); $60 \mu \mathrm{M}$ (blue); $150 \mu \mathrm{M}$ (red); $300 \mu \mathrm{M}$ (black). For presentational purposes, only four of the $\mathrm{Cu}^{2+}$ concentrations studied are shown in each case.

\section{a) Effect of $\left[\mathrm{Cu}^{2+}\right]$}

The rates of step $\mathrm{Y}$ were determined for a range of $\mathrm{Cu}^{2+}$ concentrations $(0 \mathrm{nM}, 25 \mathrm{nM}, 50$ $\mathrm{nM}, 2 \mu \mathrm{M}, 5 \mu \mathrm{M}, 10 \mu \mathrm{M}$ and $15 \mu \mathrm{M}$ ) in the presence of $56 \mu \mathrm{M}$ GSH under atmospheric oxygen. The plot of concentrations of $-\mathrm{SH}$ against time for some of the $\mathrm{Cu}^{2+}$ concentrations studied is given in Figure 3a. The rate of $-\mathrm{SH}$ depletion $(-\mathrm{d}[-\mathrm{SH}] / \mathrm{dt})$ in step $\mathrm{Y}$ is plotted against $\mathrm{Cu}^{2+}$ concentrations as displayed in Figure 4. The result shows that the rate of GSH (-copper complex) oxidation increases with $\mathrm{Cu}^{2+}$ concentrations. Similar studies were performed for $100 \mu \mathrm{M}$ GSH in the presence of atmospheric oxygen. It was also observed that the rate increases as the concentration of $\mathrm{Cu}^{2+}$ increases. However, the extents to which the rates increase with $\left[\mathrm{Cu}^{2+}\right]$ are different for the different GSH concentrations studied. Hence, the order of reaction with respect to concentration of $\mathrm{Cu}^{2+}$ cannot be readily determined. This likely arises due to involvement of $\mathrm{Cu}^{2+}$ in more than one reaction routes, as will be discussed later. 


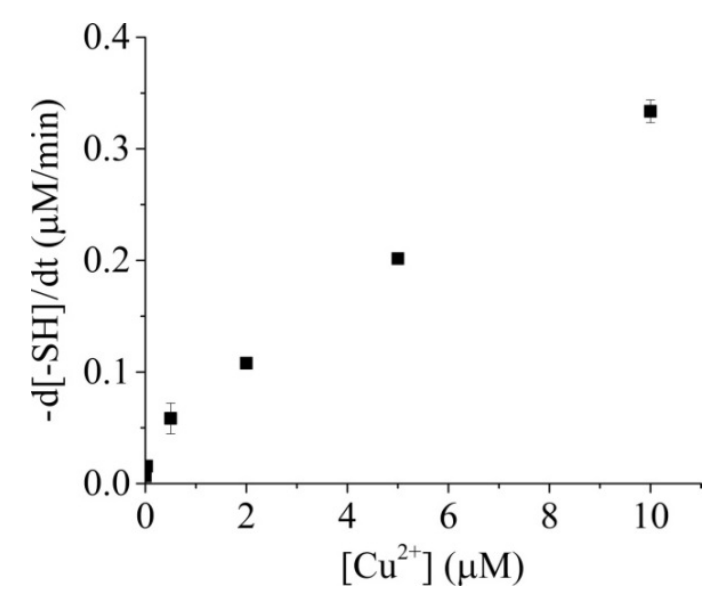

Figure 4: The rates of -SH depletion (-d[-SH]/dt) during step $\mathrm{Y}$ as a function of $\mathrm{Cu}^{2+}$ concentrations studied in the solutions containing $56 \mu \mathrm{M}$ GSH and varied concentrations of $\mathrm{Cu}^{2+}: 0 \mathrm{nM}, 25 \mathrm{nM}, 50$ $\mathrm{nM}, 2 \mu \mathrm{M}, 5 \mu \mathrm{M}, 10 \mu \mathrm{M}$ and $15 \mu \mathrm{M}$, in the presence of atmospheric $(0.27 \mathrm{mM}) \mathrm{O}_{2}$.

\section{b) Effect of $\left[\mathrm{O}_{2}\right]$}

Two different concentrations of $\mathrm{O}_{2}$, atmospheric $(0.27 \mathrm{mM})$ and saturated $(1.24 \mathrm{mM})$, were used to study its effect on the rate of step Y. The results for the reaction mixtures of $56 \mu \mathrm{M}$ GSH and $7.5 \mu \mathrm{M} \mathrm{Cu}^{2+}$ are shown in Figure 5. The rates of step Y reactions are $0.312 \pm 0.008$ $\mu \mathrm{M} \mathrm{m^{-1 }}$ and $0.718 \pm 0.021 \mu \mathrm{M} \mathrm{min}^{-1}$ for atmospheric and saturated oxygen respectively. At the same time, similar experiments were performed for $100 \mu \mathrm{M}$ GSH and $7.5 \mu \mathrm{M} \mathrm{Cu}{ }^{2+}$ mixtures to give the step $\mathrm{Y}$ rates of $0.211 \pm 0.006 \mu \mathrm{M} \mathrm{min}^{-1}$ and $0.464 \pm 0.023 \mu \mathrm{M} \mathrm{min}^{-1}$ in the presence of atmospheric and saturated oxygen respectively. The results studied in both GSH concentrations indicate that the rate of step $\mathrm{Y}$ reaction is $(0.53 \pm 0.04)^{\text {th }}$ order with respect to the $\mathrm{O}_{2}$ concentration.

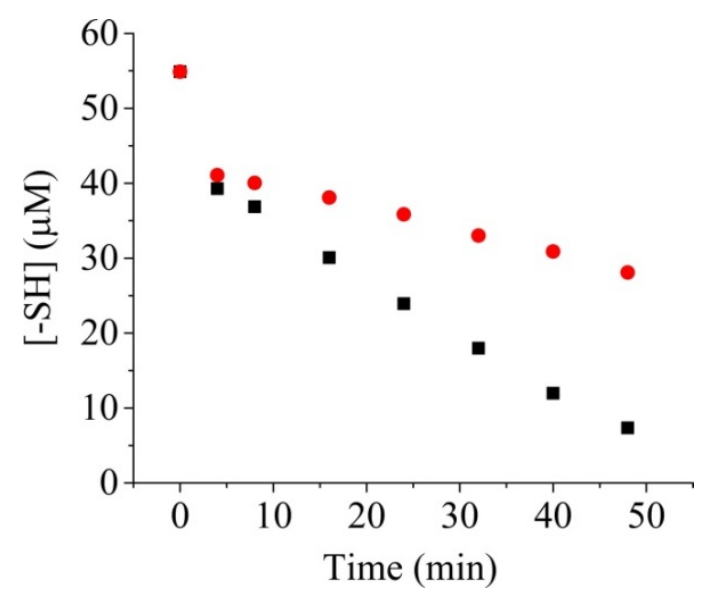

Figure 5: The concentration of free thiols $(-\mathrm{SH})$ at different experimental times for the solution mixtures of $56 \mu \mathrm{M} \mathrm{GSH}, 7.5 \mu \mathrm{M} \mathrm{Cu}^{2+}$ and varied concentrations of $\mathrm{O}_{2}$ : atmospheric $(0.27 \mathrm{mM}) \mathrm{O}_{2}$ (red); saturated (1.24 mM) $\mathrm{O}_{2}$ (black)

The results of kinetic studies suggest the clear positive dependence of the rate of GSH oxidation on both $\left[\mathrm{Cu}^{2+}\right]$ and $\left[\mathrm{O}_{2}\right]$. This indicates the involvements of these two species in or prior to the rate-determining step (RDS). 
More specifically, the kinetic studies showed that the rate of step $\mathrm{Y}$ reaction is proportional to the square root of $\mathrm{O}_{2}$ concentration $\left(-\mathrm{d}[-\mathrm{SH}] / \mathrm{dt} \alpha\left[\mathrm{O}_{2}\right]^{0.5}\right)$. This relationship is consistent with a pre-equilibrium step involving the copper-glutathione complex ('A') and $\mathrm{O}_{2}$ in the stoichiometric ratio of 2:1 to form another different complex with one less electron, ' $\mathrm{B}$ ' (eqn. 6). This may be followed by the rate-determining conversion of ' $\mathrm{B}$ ' to the final product of GSH oxidation, which has been reported to be GSSG $^{[21]}$ (eqn. 7). The derived rate law is given in eqn. 10.

$$
\begin{aligned}
& \mathrm{A}+\frac{1 / 2 \mathrm{O}_{2} \stackrel{K}{\rightleftharpoons} \mathrm{B}+1 / 2 \mathrm{H}_{2} \mathrm{O}_{2}}{\longrightarrow} \stackrel{k^{\prime}}{\longrightarrow} \mathrm{Cu}^{2+}+\mathrm{GSSG} \\
& K=\frac{[\mathrm{B}]\left[\mathrm{H}_{2} \mathrm{O}_{2}\right]^{0.5}}{[\mathrm{~A}]\left[\mathrm{O}_{2}\right]^{0.5}} \\
& v=k^{\prime}[\mathrm{B}] \\
& v=\frac{k^{\prime} \mathrm{K}[\mathrm{A}]\left[\mathrm{O}_{2}\right]^{0.5}}{\left[\mathrm{H}_{2} \mathrm{O}_{2}\right]^{0.5}}
\end{aligned}
$$

where [i] denotes the concentration of species $i . K$ is the equilibrium constant of the oxidation of ' $\mathrm{A}$ ' to ' $\mathrm{B}$ ' by $\mathrm{O}_{2} . v$ and $k^{\prime}$ are the rate of reaction and rate constant for the conversion of ' $\mathrm{B}$ ' to $\mathrm{Cu}^{2+}$ and GSSG respectively. [A] is the concentration of the 1:2 Cu-SG complex formed in excess of GSH, [A] is thus equivalent or proportional to the concentration of $\mathrm{Cu}^{2+}$. The suggested mechanism for step $\mathrm{Y}$ reaction is therefore consistent with the dependence of the rate of GSH oxidation on $\mathrm{Cu}^{2+}$ concentration.

\section{c) Effect of [GSH]}

The rates of the step $\mathrm{Y}$ reactions were investigated for varied concentrations of GSH in solutions containing $10 \mu \mathrm{M} \mathrm{Cu}^{2+}$ under atmospheric $\mathrm{O}_{2}$. The rates of free thiol consumption $(-\mathrm{d}[-\mathrm{SH}] / \mathrm{dt})$ are plotted against GSH concentration, as shown in Figure 6. The results show a decreasing rate of reaction as the concentration of GSH increases.

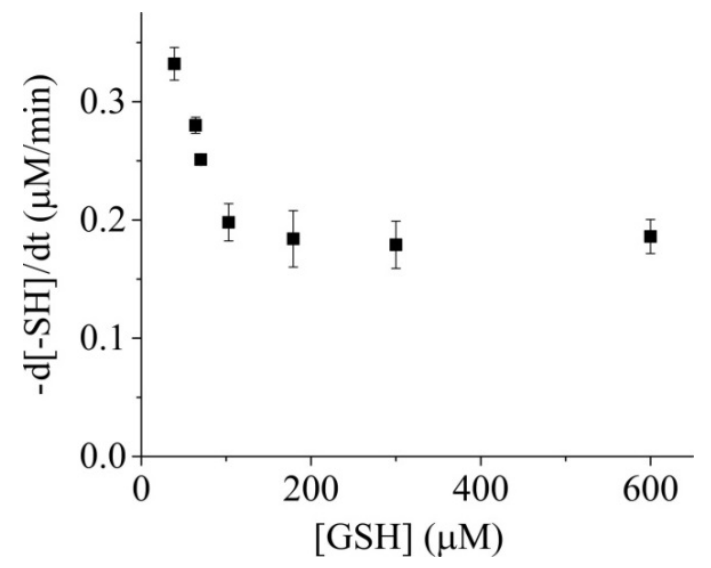

Figure 6: The rates of $-\mathrm{SH}$ depletion (-d[-SH]/dt) during step $\mathrm{Y}$ as a function of GSH concentrations studied in the solutions containing $10 \mu \mathrm{M} \mathrm{Cu}^{2+}$ and varied concentrations of GSH: $39 \mu \mathrm{M}, 64 \mu \mathrm{M}, 70$ $\mu \mathrm{M}, 103 \mu \mathrm{M}, 179 \mu \mathrm{M}, 300 \mu \mathrm{M}$ and $600 \mu \mathrm{M}$, in the presence of atmospheric $(0.27 \mathrm{mM}) \mathrm{O}_{2}$. 
In contrast to the response to $\left[\mathrm{Cu}^{2+}\right]$ and $\left[\mathrm{O}_{2}\right]$, the rate of step $\mathrm{Y}$ reaction decreases with increasing concentration of GSH. The unusual behaviour suggests the existence of a competing, parallel reaction which becomes more favourable as the GSH concentration increases and outweighs the oxidation of GSH to GSSG at sufficiently high level of GSH. Note that the lower consumption of - $\mathrm{SH}$ measured via DTNB reaction at high [GSH] suggests that the competing reaction results in the formation of a stable, inactive species with unbound thiol groups. This result is consistent with the rearrangement mechanism proposed for step y reaction.

In fact, there are at least two pathways which can potentially lead to the decrease in step Y reaction rate as the concentration of GSH increases. One is the rearrangement of copperglutathione complex into a different form which is inactive to the catalytic oxidation of GSH, as proposed. The other is the reduction in $\mathrm{Cu}^{2+}$ concentration.

The availability of $\mathrm{Cu}^{2+}$ can be lost from the system via different means. First is the formation of copper complex with the product, GSSG. To investigate this process, the kinetic studies on the copper-glutathione complex formation were performed, as detailed with following. The changes in UV-Vis spectra as a function of time were investigated for three different cases: GSSG $+\mathrm{Cu}^{2+}, \mathrm{GSH}+\mathrm{Cu}^{2+}$ (with and without $\mathrm{O}_{2}$ ) and GSSG $+\mathrm{GSH}+\mathrm{Cu}^{2+}$, which unless stated otherwise studied under atmospheric oxygen.

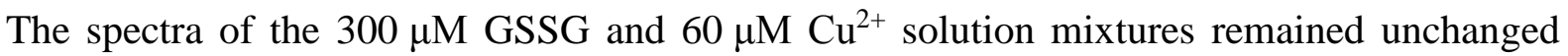
over the 40 min course of study. In contrast, the spectra of $600 \mu \mathrm{M} G S H$ and $60 \mu \mathrm{M} \mathrm{Cu}^{2+}$ showed increasing absorbance at $297 \mathrm{~nm}$ as a function of time, refer to Figure 7. There is a small but insignificant difference in the rates in the absence and presence of $\mathrm{O}_{2}(<1 \%)$. The formation of this complex is thus predominantly independent of the $\mathrm{O}_{2}$ concentration.

Addition of $300 \mu \mathrm{M}$ GSSG to the $600 \mu \mathrm{M}$ GSH and $60 \mu \mathrm{M} \mathrm{Cu}^{2+}$ mixtures results in ca. 15\% reduction in $\mathrm{Cu}-\mathrm{GSH}$ complex formation rates. Note that for the initial GSH concentration of $600 \mu \mathrm{M}$, the highest possible concentration of GSSG formed is $300 \mu \mathrm{M}$, the concentration of which is unlikely to be reached due to the equilibrium state and the loss of GSH in the formation of complexes. The small decrease in the rates of $\mathrm{Cu}-\mathrm{GSH}$ complex formation even with the large amount of GSSG added implies that GSSG is not the dominant factor that causes the reduction in GSH oxidation rates as the concentration of GSH increases. This indicates that although $\mathrm{Cu}^{2+}$ can form complexes with GSSG, in the presence of both GSH and GSSG, $\mathrm{Cu}^{2+}$ favourably binds to GSH. There is therefore a minor effect from $\mathrm{Cu}^{2+}$-GSSG complex if formed. Additional evidence that GSSG has no observable effect on the rate of GSH oxidation was confirmed by the studies of the rate of the decrease in -SH concentration measured by DTNB. This result is included in the Supporting Information. 


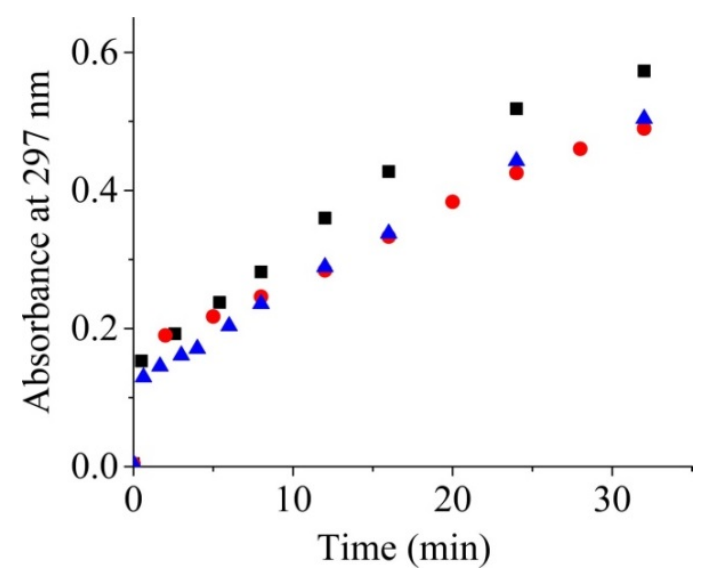

Figure 7: The values of absorbance at $297 \mathrm{~nm}$ as a function of experimental time. $600 \mu \mathrm{M}$ GSH and $60 \mu \mathrm{M} \mathrm{Cu}^{2+}$ in the absence of $\mathrm{O}_{2}$ (blue); $600 \mu \mathrm{M} \mathrm{GSH}$ and $60 \mu \mathrm{M} \mathrm{Cu}^{2+}$ in the presence of atmospheric $\mathrm{O}_{2}$ (black); $600 \mu \mathrm{M} \mathrm{GSH}, 300 \mu \mathrm{M} \mathrm{GSSG}$ and $60 \mu \mathrm{M} \mathrm{Cu}^{2+}$ in the presence of atmospheric $\mathrm{O}_{2}$ (red).

The second possible route for the loss of $\mathrm{Cu}^{2+}$ in solution is the reactions of $\mathrm{Cu}^{2+}$ with other species in the solution such as $\mathrm{H}_{2} \mathrm{O}_{2}$ (very low concentration i.e. not detectable via DTNB, as evidenced in the Supporting Information) and the solvent, $\mathrm{H}_{2} \mathrm{O}$, to form copper oxides. This is however endergonic under the reaction conditions employed (calculated from the values of standard potentials of the half-reactions involved). ${ }^{[22]}$ Therefore, there is no mechanisms, to the authors' best knowledge, which can be responsible for the decreasing rates of GSH oxidation at higher GSH concentrations other than the rearrangement of the copperglutathione complex (cysteine thiol-bound) to its inactive form (glutamic/glycine-bound).

Following all the above information together with that obtained from the variation of GSH oxidation rates as a function of various experimental parameters, we propose a step-wise mechanism shown in Figure 8. 


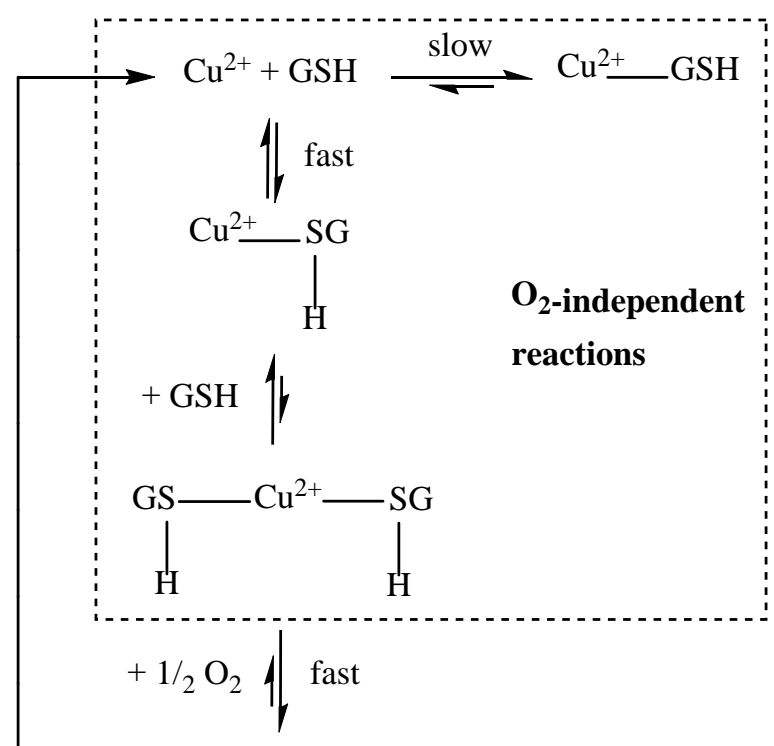

$$
\text { A }+1 / 2 \mathrm{H}_{2} \mathrm{O}_{2}
$$

$+1 /{ }_{2} \mathrm{O}_{2} \| K$

$$
\text { B }+1 / 2 \mathrm{H}_{2} \mathrm{O}_{2}
$$

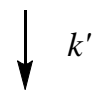

$\mathrm{Cu}^{2+}+\mathrm{GSSG}$

A<smiles>[SiH3][Cl+][SiH3]</smiles>

B<smiles>[AsH2][C+][AsH2]</smiles>

Figure 8: The proposed mechanisms for the oxidation of GSH catalyzed by copper(II) and the proposed structures of the intermediate complexes 'A' and 'B.'

It has been reported that when the molar ratio of $\mathrm{GSH}: \mathrm{Cu}^{2+}$ is equal to or greater than $3: 1$, corresponding to conditions in all of the experiments studied in this paper, a GS-Cu(I)-SG complex is swiftly formed. ${ }^{[18,21]}$ However, as discussed before in Section 3.3b that a preequilibrium step is required prior to the rate-determining formation of GSSG. We therefore tentatively propose the structure of ' $A$ ' as presented in Figure 8. Note that our proposed structure of ' $A$ ' has the same overall oxidation state as the GS-Cu(I)-SG complex previously reported. ${ }^{[18,21]}$ The only difference is how the electrons might be distributed between copper and sulfur in the $\mathrm{Cu}-\mathrm{S}$ bond. Following 'A,' the proposed structure of the intermediate oxidation product ' $\mathrm{B}$,' is given in Figure 8. 


\section{Conclusions}

The kinetics of glutathione oxidation reaction catalyzed by copper(II) have been investigated and step-by-step mechanisms proposed. The results emphasize that GSH is not auto-oxidized by oxygen in the absence of a catalyst. In the presence of $\mathrm{Cu}^{2+}$, two-step reactions were observed in both the absence and presence of $\mathrm{O}_{2}$. The first steps ( $x$ and $\mathrm{X}$ ) involve the formation of copper-glutathione complexes. In the absence of $\mathrm{O}_{2}$, the stoichiometry of $\mathrm{Cu}$ GSH complex is 1:1. With $\mathrm{O}_{2}$ present, the 1:2 Cu:GSH complex is formed. The second step (Y) is the overall oxidation of GSH to GSSG catalyzed by copper(II). The rates of GSH oxidation in the second step increase with increasing concentrations of the oxidizing agent, $\mathrm{O}_{2}$, and the catalyst, $\mathrm{Cu}^{2+}$, but decrease when the concentration of GSH itself is increased. This inverse relationship is suggested to be a result of competing formation of an inactive form of copper-glutathione complex.

In this paper, we have thus provided insights into the mechanistic details of the copper(II)catalyzed oxidation of GSH. The understanding of this process will be beneficial towards the studies of the roles of copper and glutathione in biological systems as well as the development of sample preparation procedures for bioanalysis. Among human biological specimens, it has been reported that plasma GSH levels decrease quickly with the half-life of less than 20 min. ${ }^{[23]}$ Meanwhile, saliva samples show more promising performance in terms of the stability of GSH. ${ }^{[24]}$ The variation in GSH stability in biological samples may be attributed to the different concentrations and activity of copper(II) as well as other metal and biological catalysts in different samples, the work of which requires further studies.

\section{Acknowledgements}

KN receives funding from the Royal Thai government (DPST scholarship). KN, CBM and RGC are sponsored by the funding from the European Research Council under the European Union's Seventh Framework Programme (FP/2007-2013)/ERC Grant Agreement no. [320403].

\section{References}

[1] aJ. P. Richie, Jr., L. Skowronski, P. Abraham, Y. Leutzinger, Clin. Chem. 1996, 42, 64-70; bM. Nassar, N. Hiraishi, M. S. Islam, M. Otsuki, J. Tagami, J. Dent. Sci. 2014, 9, 85-90.

[2] aA. Deiss, Ann. Intern. Med. 1970, 73, 413; bR. Osterberg, R. Ligaarden, D. Persson, J. Inorg. Biochem. 1979, 10, 341-355.

[3] aI. Jiménez, H. Speisky, J. Trace Elem. Med Biol. 2000, 14, 161-167; bP. M. Hanna, R. P. Mason, Arch. Biochem. Biophys. 1992, 295, 205-213.

[4] aL. Milne, P. Nicotera, S. Orrenius, M. J. Burkitt, Arch. Biochem. Biophys. 1993, 304, 102-109; bN. Spear, S. D. Aust, Arch. Biochem. Biophys. 1995, 317, 142-148.

[5] C. Carrasco-Pozo, M. E. Aliaga, C. Olea-Azar, H. Speisky, Bioorg. Med. Chem. 2008, 16, 9795-9803.

[6] aH. Speisky, M. Gomez, C. Carrasco-Pozo, E. Pastene, C. Lopez-Alarcon, C. OleaAzar, Bioorg. Med. Chem. 2008, 16, 6568-6574; bH. Speisky, M. Gomez, F. BurgosBravo, C. Lopez-Alarcon, C. Jullian, C. Olea-Azar, M. E. Aliaga, Bioorg. Med. Chem. 2009, 17, 1803-1810.

[7] A. V. Kachur, C. J. Koch, J. E. Biaglow, Free Radic. Res. 1998, 28, 259-269.

[8] P. W. Riddles, R. L. Blakeley, B. Zerner, Methods Enzymol. 1983, 91, 49-60.

[9] R. P. Szajewski, G. M. Whitesides, J. Am. Chem. Soc. 1980, 102, 2011-2026. 
[10] R. Battino, T. R. Rettich, T. Tominaga, J. Phys. Chem. Ref. Data 1983, 12, 163.

[11] R. L. Pecosk, Anal. Chem. 1953, 25, 561-564.

[12] O. Warburg, Heavy Metal Prosthetic Groups and Enzyme Action, Oxford : Clarendon Press, 1949.

[13] aN. Zhang, Q. Zhou, X. Yin, D. Zeng, J. Solution Chem. 2014, 43, 326-339; bM. C. Areias, K. Shimizu, R. G. Compton, The Analyst 2016, 141, 2904-2910.

[14] aV. G. Shtyrlin, Y. I. Zyavkina, V. S. Ilakin, R. R. Garipov, A. V. Zakharov, J. Inorg. Biochem. 2005, 99, 1335-1346; bJ. Z. Pederson, C. Steinkuhler, U. Weser, G. Rotilio, BioMetals 1996, 9, 3-9.

[15] aS. T. Chow, C. A. McAuliffe, B. J. Sayle, J. Inorg. Nucl. Chem. 1975, 37, 451-454; bM. Ahmed, World Appl. Sci. J. 2014, 29, 1357-1362.

[16] A. Krezel, W. Bal, Acta Biochim. Pol. 1999, 46, 567-580.

[17] R. Bregier-Jarzebowska, J. Solution Chem. 2014, 43, 2144-2162.

[18] A. Corazza, I. Harvey, P. J. Sadler, Eur. J. Biochem. 1996, 236, 697-705.

[19] R. C. Smith, V. D. Reed, W. E. Hill, Phosphorus, Sulfur Silicon Relat. Elem. 1994, 90, 147-154.

[20] F. J. Millero, F. Huang, T. B. Graham, J. Solution Chem. 2003, 32, 473-487.

[21] M. E. Aliaga, C. Carrasco-Pozo, C. López-Alarcón, H. Speisky, Transition Met. Chem. 2010, 35, 321-329.

[22] A. J. Bard, R. Parsons, J. Jordan, Standard Potentials in Aqueous Solution, Taylor \& Francis, 1985.

[23] E. Beutler, O. Duron, B. M. Kelly, J. Lab. Clin. Med. 1963, 61, 882-888.

[24] E. Emekli-Alturfan, A. Yarat, E. Caliskan-Ak, R. Pisiriciler, B. Kuru, U. Noyan, J. Clin. Lab. Anal. 2013, 27, 261-266. 


\section{Graphical abstract}

Copper-Glutathione mystery solved: Copper(II) alters the concentration of an antioxidant GSH by forming a metal complex and catalyzes GSH oxidation. The self-inhibiting nature and the rate law of the process deduced in this work allow the understanding of the copperrelated consumption of GSH in human body and further contribute to the development of biosensors.<smiles>C=CCC(C)C(=O)O</smiles> 